SIMPÓSIO DOS PROFISSIONAIS DA UNICAMP

\section{INSTITUCIONALIZACC̃̃O DO SUPORTE A PROJETOS CULTURAIS DA COMUNIDADE UNIVERSITÁRIA}

ELIANA SILVA PAIFER, CARMEN LÚCIA RODRIGUES ARRUDA, DANILO MELLO NEGRETI, FABIO AUGUSTO CERQUEIRA, HERIVELTON FABIANO ZANOTTO

REIT - REITORIA;PRE - PRO-REITORIA DE EXTENSAO E ASSUNTOS COMUNITARIOS;DIRCUL - DIRETORIA DE CULTURA

\title{
Introdução:
}

DOI: $10.20396 /$ sinteses.v0i7.10189

A Universidade Estadual de Campinas possui uma enorme gama de produções artístico-culturais, muitas delas realizadas de forma autônoma por pessoas de sua comunidade acadêmica, de todos os segmentos - docentes, estudantes, técnico-administrativos e pesquisadores. O site Guia Cultural Unicamp, oferece dados para o entendimento dessa dimensão. Muitos desses projetos são realizados sem qualquer tipo de suporte institucional, ou buscam esse apoio fazendo solicitações pontuais em diferentes instâncias da Universidade. Com este projeto criou-se um fluxo de procedimentos para essa demanda, amplificando seu alcance e estabelecendo regras claras, que permitiram o acesso qualificado e igualitário para toda a comunidade universitária ao suporte logístico e financeiro disponibilizado.

\section{Metodologia:}

Por meio de uma chamada para apoio a projetos culturais, docentes, pesquisadores, técnico-administrativos e estudantes da Unicamp puderam submeter proposta, com regras estabelecidas e prazo de submissão, a fim de serem selecionados por comissão avaliadora específica para esse fim. Os projetos selecionados passaram por trâmites burocráticos institucionalmente estabelecidos para atendimento da demanda e realização efetiva das ações.

\section{Resultados:}

A Institucionalização do suporte a projetos culturais da comunidade universitária, possibilitou: Atendimento qualificado e igualitário às demandas de apoio a projetos culturais; Estabelecer o fluxo de procedimentos para o acesso desses projetos ao apoio institucional, e o direcionamento das necessidades desses projetos aos demais órgãos da Unicamp, como DGA, Prefeitura do Campus, entre outros; Ampliar e qualificar as ações artístico-culturais promovidas pela comunidade interna da Unicamp e valorizar e disseminar a cultura, em sua definição mais ampla, pelas comunidades interna e externa. Todas as sequências do projeto foram objeto de análises prévias, controles e registros visando o aperfeiçoamento do processo em novas edições. O projeto trouxe muita reflexão da equipe envolvida quanto aos métodos e procedimentos adotados e isso possibilitou a revisão do Edital de chamada para apoio a projetos culturais e a implementação de uma nova estratégia para a edição 2019 , objetivando dinamizar o acesso aos recursos e disponibilização de materiais e serviços aos contemplados.

\section{Considerações finais:}

A ProEC/DCult apoiou vinte e um projetos culturais em sua primeira edição e dentre as produções apoiadas contamos com documentários, exposições, mostra de cinema, espetáculos teatrais, dança, música e outros. Para a segunda edição da chamada para apoio a projetos culturais inserimos nos critérios de avaliação pontuação para afinidades com as temáticas relacionadas às culturas afro americanas e indígenas atendendo a nova política da Diretoria de Cultura de incentivo as diversidades culturais.
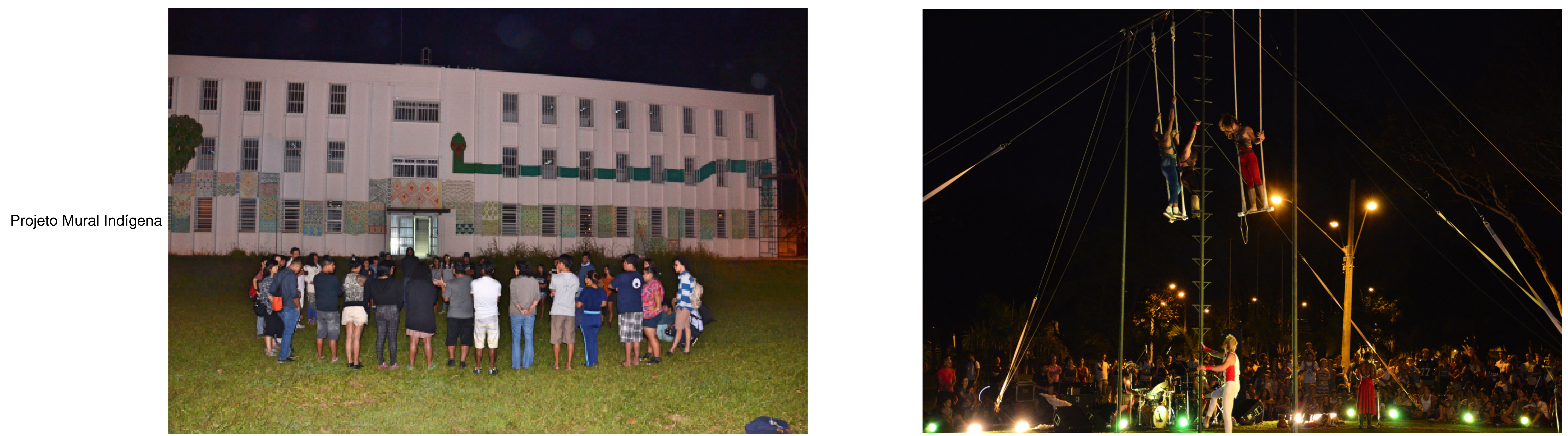